\title{
Sex differences in recombination and mapping adaptations
}

\author{
Patrick D. Lorch \\ Zoology Department, University of Toronto, Ramsay Wright Labs, 25 Harbord St. Toronto, Ontario \\ M5S 3G5, Canada (Phone: (919)843-2320; Fax: (919)962-1625; E-mail: plorch@email.unc.edu); \\ Current address: Biology Department, University of North Carolina, CB 3280, Coker Hall, Chapel Hill, \\ NC 27599-3280, USA
}

Received 15 April 2002 Accepted 15 September 2003

Key words: condition dependence, good genes, QTL mapping, sexual selection, sexual conflict

\begin{abstract}
Since the raw material of marker based mapping is recombination, understanding how and why recombination rates evolve, and how we can use variation in these rates will ultimately help to improve map resolution. For example, using this variation could help in discriminating between linkage and pleiotropy when QTL for several traits co-locate. It might also be used to improve QTL mapping algorithms. The goals of this chapter are: (1) to highlight differences in recombination rates between the sexes, (2) describe why we might expect these differences, and (3) explore how sex difference in recombination can be used to improve resolution in QTL mapping.
\end{abstract}

\section{Sex differences in recombination}

Sex differences in recombination rates generally are seen as differences in linkage maps (Figure 1). Since the physical size of chromosomes in each sex is assumed to be equal, sex differences in recombination result from different amounts of recombination during meiosis. These sex differences become apparent whenever mapping studies are conducted in such a way that recombination rates can be estimated separately for each sex. Taking a backcross design as an example (see Korol, Preygel \& Preygel, 1994), the F1 generation produced by crossing two different inbred lines can be used as both sires and dams (pollen parent and seed parent) in the backcross to original inbred parentals. Sex difference in recombination can then be seen in the linkage maps produced from the two sets of backcross offspring. This is because inbred backcross parents should be homozygous at almost all loci, so any recombination occurs in the F1 parent. If half of your backcrosses use F1 dams and the other F1 sires, you can estimate linkage maps separately for each sex.

A survey of published literature shows that sex differences in recombination rates are widespread (for reviews see Callan \& Perry, 1977; Trivers, 1988; Burt, Bell \& Harvey, 1991; Singer et al., 2002). Table 1 and Figure 2 summarize all the data to date (The Appendix shows data collected since Burt, Bell \& Harvey (1991) in a format similar to their appendix.). Where sex differences in recombination have been estimated, we can distinguish between species where both sexes experience some recombination (chiasmate species) and species where one sex has no recombination (achiasmate species). In chiasmate species 45 cases show more female than male recombination, 21 cases show more male than female recombination and 9 cases show no sex difference (Cano \& Santos, 1990; Burt, Bell \& Harvey, 1991; van Oorschot et al., 1992; Korol Preygel \& Preygel, 1994; Lagercrantz \& Lydiate, 1995; Kearsey et al., 1996). In achiasmate species 5 cases show female recombination, 8 cases show male recombination, and whenever there are heterogametic sex chromosomes, the heterogametic sex has no recombination (Burt, Bell \& Harvey, 1991).

Whatever the causes of these sex differences, they provide a useful example of variation in recombination rates for two reasons. First, the 


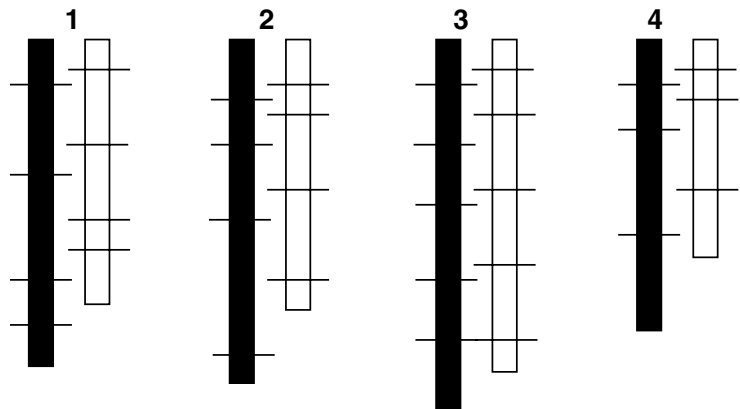

Figure 1. Typical pattern of sex-specific maps for four linkage groups in a hypothetical species. Male and female chromosomes should be of equal length, but maps often show sex differences. Bars show genetic marker loci. Distance between markers indicates larger numbers of recombination events between markers. Typically, female maps (black) are larger than male maps (white) due to more and/or less-localized recombination events.

Table 1. Breakdown of sex differences in recombination for 75 species by taxon. Lists chiasmate species, based on data in Burt, Bell and Harvey (1991) and the Appendix

\begin{tabular}{lccll}
\hline Taxon & $\mathrm{F}>\mathrm{M}$ & $\mathrm{M}>\mathrm{F}$ & $\mathrm{F}=\mathrm{M}$ & Comments \\
\hline Animals & & & & \\
$\quad$ Platyhelminthes & 2 & 1 & 0 & \\
Insecta & 2 & 9 & 3 & All \\
& & & & Orthoptera \\
Amphibia & 4 & 2 & 0 & \\
Mammalia & 7 & 4 & 1 & \\
Pisces & 2 & 0 & 0 & \\
Aves & 2 & 0 & 0 & \\
Plants & & & & \\
$\quad$ Monocotyledonae & 20 & 3 & 4 & \\
$\quad$ Dicotyledonae & 2 & 1 & 1 & \\
$\quad$ Orchidaceae & 4 & 1 & 0 & \\
Total & 45 & 21 & 9 & \\
\hline
\end{tabular}

evolution of modifiers of recombination has been studied extensively in the context of the evolution of sex. This means that we have basic theory for understanding how recombination rates can be modified, albeit few specifics about how sex difference can arise. Second, by modifying breeding designs we may be able to exploit sex differences in recombination to improve map resolution and QTL discrimination (Singer et al., 2002). This is not to say that other forms of variation in recombina-

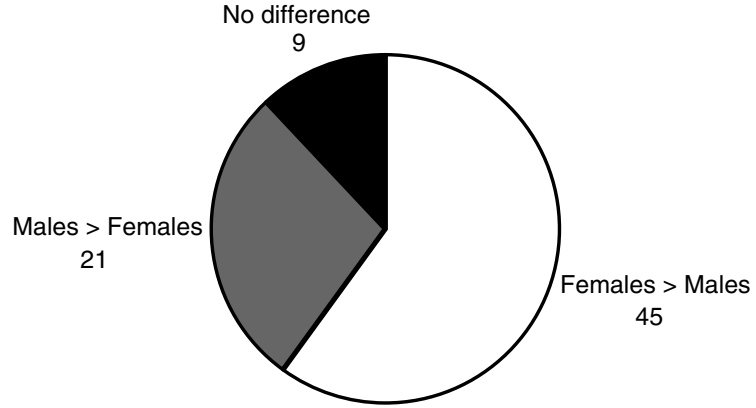

Figure 2. Summary of species where sex differences in recombination have been estimated. For chiasmate species, based on data in Burt, Bell and Harvey (1991) and the Appendix.

tion rates cannot also be used to improve maps, only that since QTL mapping involves crosses and algorithmic estimation of QTL location relative to a marker-based map, sex difference may provide a particularly useful form of variation in recombination rates. To make this second point clear we need to consider what we know about how recombination rates evolve.

\section{How recombination rates can evolve}

The evolution of recombination is difficult to study because recombination affects the way genes on the same chromosome interact. As evolution proceeds, recombination does three things, the first two of which directly conflict. It can bring together alleles on one chromosome with positive effects on fitness, allowing one parent to pass along sets of alleles that survived natural and sexual selection in the parents. Recombination can then break up these beneficial associations in the very next generation. It can also bring together deleterious alleles, allowing them to be more efficiently eliminated by selection. The complicated balance between these three processes will determine whether selection acts to increase or decrease recombination rates for a given region of a chromosome (Barton, 1995). Selection can act to increase recombination between some genes under some circumstances and to decrease recombination between another (possibly overlapping) set of genes under other circumstances.

Since the evolution of recombination rates depends on gene interactions, the nature of 
interactions must be taken into account. In other words, it is important to know whether epistatic effects of groups of alleles on fitness are positive or negative, increasing fitness more or less than the independent affect of alleles at each locus. If we consider a pair of alleles that interact to affect fitness, strong epistatic interactions and strong selection will generally select for decreased recombination (Barton, 1995; Otto \& Michalakis, 1998; Phillips, Otto \& Whitlock, 2000). This is because recombination increases the likelihood of bringing together strongly deleterious mutations. Under this scenario, selection for increased recombination can only occur when epistasis and selection are weak relative to rates of recombination. When this is the case, Figure 3 (Barton, 1995; Phillips, Otto \& Whitlock, 2000) shows when selection will increase or decrease recombination.

This picture predicts when an allele that increases recombination rate between a focal set of alleles will increase or decrease in frequency. For example, recombination rate is more likely to increase between members of a set of alleles if they exhibit negative epistasis and relatively strong negative fitness effects (gray region on left in Figure 3). This is because with these param-

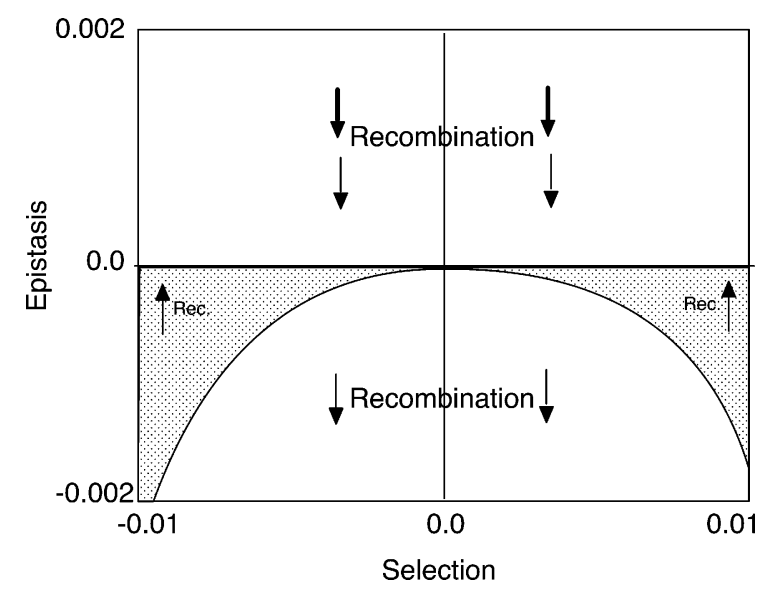

Figure 3. Evolution of recombination rate without considering sex differences, for weak selection and weak epistasis. Whether selection will act to increase or decrease recombination between members of a set of loci depends on the combined effect of the alleles at each locus on fitness and on the nature of epistatic interactions between these alleles. Epistasis is positive when the effect of focal alleles together is greater than the product of the independent effects of those alleles and negative when the combined effect of the alleles is less than the product of each separate effect. (Modified from Phillips et al., 1999.) eters, selection reduces genetic variance for fitness while less effectively removing individuals with multiple deleterious mutations. Recombination creates offspring with fewer than average deleterious mutations, favoring the evolution of increased recombination. Similarly, when interacting genes increase fitness, but show negative epistasis (gray region on right in Figure 3), selection favors recombination which breaks up groups of alleles interacting with negative epistasis. Recombination rate is likely to decrease when alleles interact with relatively strong positive epistasis (upper part of Figure 3). Differences in the way sets of loci along each chromosome interact can lead to the recombination hot-spots and dead-spots seen empirically. This picture was developed to understand the evolution of sex generally, and it treats the effects of sets of alleles in males and females as the same. However, we can use this picture as the basis for understanding how sex differences in recombination can evolve. First we must consider how selection on recombination may differ in males and females.

\section{How sex differences in recombination can evolve}

Korol, Preygel and Preygel (1994) list three hypotheses to explain the evolution of sex differences in recombination rates. The first two fail to explain large fractions of the pattern of sex differences seen in nature. First, higher metabolic activity in females and the resulting increased rate of oxidative damage during oogenesis may require higher rates of recombinational repair in females (Bernstein, Hopf \& Michod, 1988, p. 151). This hypothesis does not explain cases where there is higher recombination in males (21 of 75 species), particularly in Orthoptera ( 9 of 14), and Lepidoptera and Trichoptera (all 7; Cano and Santos, 1990; Burt, Bell \& Harvey, 1991). Second, selection for linkage of genes involved in sex determination and differentiation can lead to sex difference in recombination (Haldane, 1992; Nei, 1969). Once there is more than one gene involved in sex determination, there will be strong selection to link these genes together. A modifier of recombination which reduced recombination throughout the genome should increase in frequency. This hypothesis predicts that the sex with lower (or no) 
recombination will be the heterogametic sex. In achiasmate species this prediction is always supported (in 13 species; Burt, Bell \& Harvey, 1991). However, in chiasmate species, the prediction often does not hold (14 of 25 species; Cano \& Santos, 1990; Burt, Bell \& Harvey, 1991; van Oorschot, 1992). Though these hypotheses may play a role in the evolution of sex differences in recombination, they are not sufficient to explain all of the known variation.

The third hypothesis is that sexual selection can cause sex difference in recombination rate. Sexual selection can result in only a subset of the gametes of one sex (typically males) contributing to offspring, either due to mate selection (Bull, 1983; Trivers, 1988) or due to gamete selection (Korol, Preygel \& Preygel, 1994). Trivers pointed out that typically, sexual selection may lead to selection for decreased recombination in male meiosis so that successful males will tend to pass along sets of successful alleles to offspring. This last hypothesis has the potential to explain more of the known variation in recombination rates with respect to sex than the other two hypotheses. All the cases where male recombination exceeds females would seem to go against this hypothesis, but as Trivers (1988) pointed out, these cases appear to be associated with large male parental investment and/or excessive male mating effort. Both of these forms of male investment can reduce the intensity of sexual selection on males and even lead to sexual selection being stronger on females (Jones et al., 2000; Jones, Walker \& Avise, 2001). So the sexual selection hypothesis may also explain the cases of higher male than female recombination rates. No quantitative analyses comparing the intensity of sexual selection and the direction and magnitude of sex differences in recombination rates have been done. Such analyses in several species would constitute a strong test of the sexual selection hypothesis.

Only one test of the sexual selection hypothesis has been attempted (Burt, Bell \& Harvey, 1991). This was a weak test for several reasons. Unfortunately, for the species where a sex difference in recombination has been measured, the relative intensity of sexual selection is generally not known. This lack of information hindered Burt et al. from testing anything but a very weak prediction based on Trivers' hypoth- esis, that sex differences in recombination should be ordered:

$$
\begin{aligned}
\text { dioecious animals } & >\text { hermaphroditic plants } \\
& >\text { hermaphroditic animals. }
\end{aligned}
$$

They found no support for this prediction. In the 54 species studied, average sexual dimorphism in recombination rates did not differ between the three ecological groups. However, the variation in the intensity of sexual selection within dioecious animals probably far exceeds the variation between the above groups. A far stronger test would be to compare recombination rates between populations or species with known difference in sexual selection intensity. There is also evidence that the sex with lower recombination rates often limits recombination to the tips of chromosomes, reducing the effect of recombination (e.g., Triturus helveticus males have fewer and more terminal crossovers than females while in $T$. cristatus, the reverse is seen; Watson \& Callan, 1963). This sort of data is not often reported and was not used by Burt, et al. Finally, taxon sampling is clearly a problem in Burt et al. - all 4 hermaphroditic animals were flatworms. This bias persists even when we add recent data on sex differences to the data collected by Burt et al. (e.g., 25 of 36 plants are from Liliaceae, 15 of 24 insects are from Orthoptera). More data are needed from a wide range of taxa so that conclusions are not biased by peculiarities of the biology of a few taxa (Coddington, 1992). Clearly, a more powerful test of the sexual selection hypothesis is needed.

\section{Sexual selection and condition dependence}

Trivers (1988) was fairly vague about exactly how sexual selection could lead to reduced recombination. He said only that '... autosomal genes enjoying reproductive success on the male side are a more restricted sample of the original set of genes with which the generation began than are the genes in breeding females.' And, 'Insofar as the actual combinations in which a male's genes appear are important to their success, then he will be selected to reduce rates of recombination (compared to females) in order to preserve these beneficial combinations.' (Trivers' italics; Trivers, 1988) We can set Trivers' idea in the context of recent theory on both evolution of recombination 
rates and sexual selection to build a more precise model of how sex difference in recombination might evolve.

When sexual selection is acting more strongly on males than females, we would not expect selection on recombination rate between members of a given set of alleles to be the same in each sex. There are two ways to visualize this. First, with sexual selection, separate plots for each sex of the relationship between recombination rate, epistasis and selection (Figure 3) might show that the gray region is larger for females than for males. For example, if females gain more than males from recombination, the gray region of the female plot would be expected to be larger. As Barton (1995) points out, more theory is needed to understand just how sexual selection will affect sex specific pressures on recombination rate. Second, the selective and epistatic effect of a set of alleles may not be the same for each sex when sexual selection is acting (Chippendale, Gibson \& Rice, 2001). So, where a given set of alleles falls on these sex-specific plots may not be the same for each sex.

The second point above is true because of the nature of sexual selection, particularly when sexually selected traits (display traits) become dependent on condition (resources available for allocation to fitness enhancing traits; Rowe \& Houle, 1996). Under strong sexual selection, exaggeration of display traits will stop if only a small number of genes are involved in display trait expression. This makes examples of extreme exaggeration of display traits difficult to understand (the 'lek paradox'; Borgia, 1979). Rowe \& Houle (1996) showed that continued exaggeration of display is possible if genetic variance in condition is 'captured' into display expression by evolving changes in life history allocation patterns. Display then becomes 'condition dependent' or 'indicates condition'. Once this happens, selection on genes related to condition is more intense in one sex than the other (sexual selection combines with existing natural selection). Selection coefficients in males will be greater than in females when sexual selection is stronger on males than females (the typical situation). This can cause divergence (along the $\mathrm{x}$ axis) of the points representing the effect of a set of alleles on recombination (Figure 3).

Epistasis is also likely to typically be stronger in males than in females. If a trait that underlies condition has some optimal value so that fitness falls off as trait value deviates from the optimum (e.g., a Gaussian function), the genes affecting that trait interact epistatically. A mutation that decreases trait value will increase fitness for some individuals and decrease fitness in others, depending on where they are in relation to the mean. By definition this is epistasis - the effects on fitness of a mutation at a given locus depend on what alleles are present at other loci affecting the trait. If selection on this trait is more intense in males, fitness will fall off more quickly with deviations from the optimum. This means that for a given set of genes, epistasis (whether positive or negative) will typically be stronger for males than for females, causing divergence (along the y-axis) of the points representing the effect of a set of alleles on recombination (Figure 3). When sexual selection is stronger on females than males, we might expect the opposite pattern of divergence along both axes as described above.

Since many (if not most) genes are likely to contribute in some way to condition, condition dependent sexual selection has the potential to affect recombination rates throughout the genome.

\section{Consequences for mapping adaptations}

Whatever the reason for the pattern, the fact is that in many organisms, sex differences in recombination rates exist. Can we use them to improve QTL mapping? In general the answer must be yes (e.g., Singer et al., 2002). Whether the improvements will be better or cheaper than simply increasing marker density remains to be seen. However, we may also be able to improve QTL placement algorithms by taking into account sex difference in recombination. This may allow gains in precision that increasing marker density cannot provide.

Even if differences between the sexes in recombination rate are not consistent across the genome (Lagercrantz \& Lydiate, 1995), setting up crosses both ways with respect to sex (as in the backcross example described earlier) can bring gains in resolution. For given regions of the genome, the cross with the highest recombination rate (largest map distances) can be used for estimating QTL location. This should bring an improvement in map resolution (see example in Box 1 for a demonstration). 
Box 1. An example using QTL Cartographer.

No current QTL programs allow for separate estimation of male and female recombination rates (though some are being developed; Korol, personal communication). However, to see some of the effects that a consistent sex difference in recombination could have, you can use QTL Cartographer (http://statgen.ncsu.edu/qtlcart/cartographer.html) to generate two linkage maps, identical except for inter-marker distances (Figure 4; using Rmap with the same random number seed and different average intermarker distances). You can then randomly place QTL onto the chromosomes (using Rqtl with the same random number seed). One is then able to generate simulated QTL data for a hypothetical cross using both maps. When you use these data to estimate QTL location, you will see that the data set based on the larger map (higher recombination rate) can give better QTL placement and resolution (Figure 5).

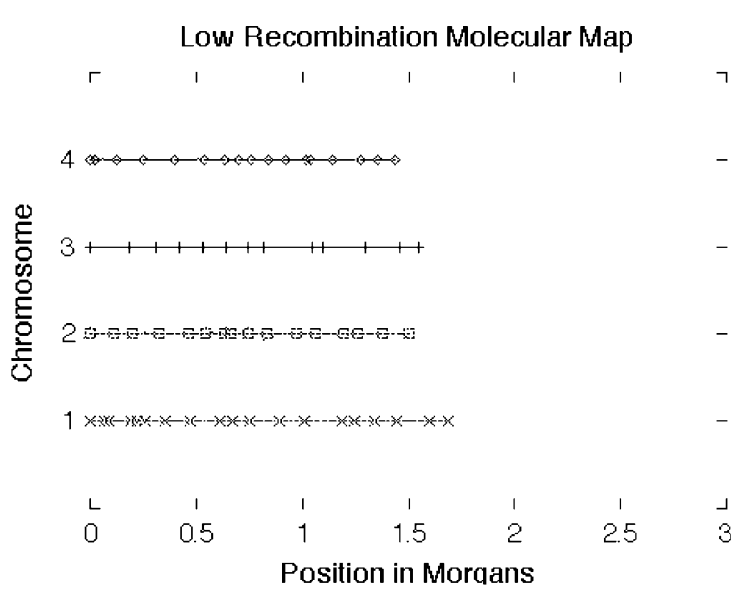

High Recombination Rate Molecular Map

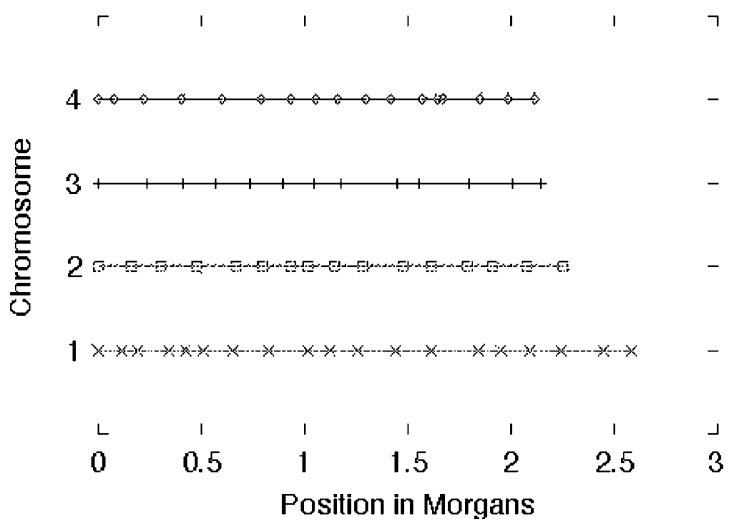

Figure 4. Maps generated using Rmap with $14 \pm 2.5$ markers ( \pm $\mathrm{SD}$ ), the mean inter-marker distance set to $10 \pm 4 \mathrm{~cm}$ for low and $15 \pm 4 \mathrm{~cm}$ for high recombination maps, and other settings left as the default values.
lowRecomb.plt results for Trait 1, Chromosome 2

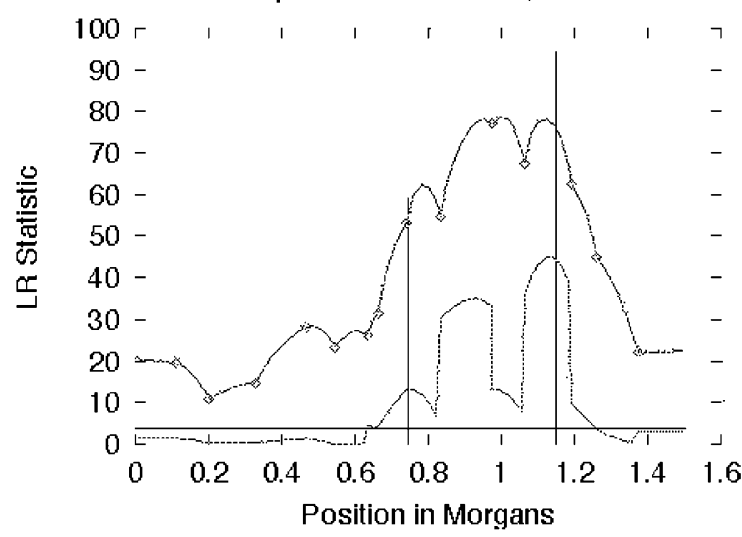

highRecomb.plt results for Trait 1, Chromosome 2

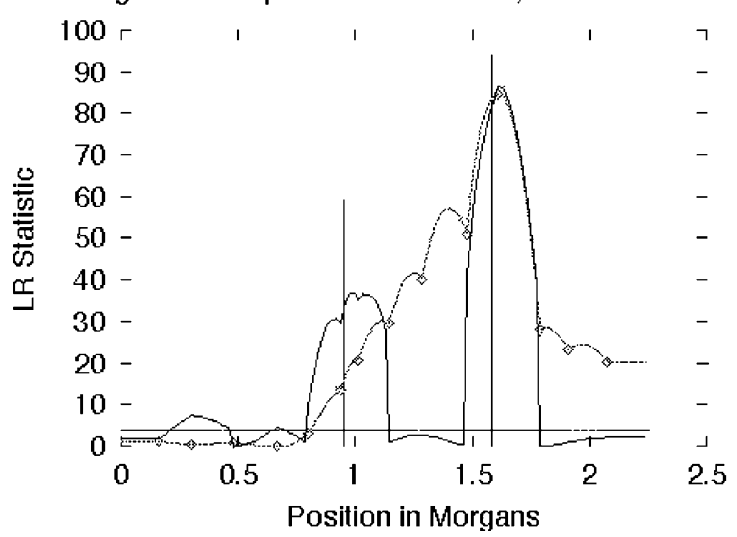

Figure 5. Likelihood ratio statistics showing QTL estimation based on low and high resolution maps. The curve with symbols is interval mapping, not controlling for residual genetic background. The other curve is using composite interval mapping and QTL Cartographer's model 6 to control for genetic background. Vertical bars represent actual QTL locations (using Rqtl) and the horizontal line is the default significance threshold (no resampling). Composite interval mapping correctly locates 2 QTL using the higher recombination rate map (lower plot), whereas the other plot shows both QTL under one peak. (Step size $=2 \mathrm{~cm}$ background parameters $=5$, window size $=10$ ).

\section{Improving QTL estimation algorithms}

Improvement in QTL discrimination may come by including sex differences in recombination into the likelihood function used to estimate QTL location relative to markers on a linkage map. The simplest way to do this, taking the backcross design as an example again, would be to use the larger estimates of recombination fractions from the crosses using each sex as the F1 parent. In other words, each type of cross will yield a different estimate of 
the distance between a given pair of markers (recombination fraction, or the relative frequency of recombination between the markers). Using the larger recombination fraction estimate for each interval will improve QTL map resolution. So for composite interval mapping (CIM), the linear regression equation used to estimate QTL positions (Liu 1998, p. 444) is

$$
y_{j}=b_{0}+b_{i} X_{i j}+\sum_{k \neq i, i+1} b_{k} X_{k j}+\varepsilon_{j},
$$

where $y_{j}$ is the quantitative trait value for individual $j, b_{0}$ is the intercept of the model, $b_{i}$ is the effect of a potential QTL between markers $i$ and $i+1, b_{k}$ is the effect of a potential QTL relative to markers other than $i$ and $i+1, X_{i j}$ and $X_{k j}$ are dummy variables taking 0 or 1 depending on the marker genotype of individual $j$, and for $X_{i j}$ on the recombination fraction of each genotype (see equation 14.59 in Liu, 1998). $\varepsilon_{j}$ is the residual from the model. Equation (1) is the basis for a likelihood function that is used to derive maximum likelihood estimates of QTL positions (equation 14.60 in Liu, 1998). These position estimates depend on $r_{1} / r$, where $r_{1}$ is the recombination between a putative QTL and marker 1 , and $r$ is the recombination fraction between marker 1 and 2 . The $r$ values are themselves estimated as part of the iterative maximum likelihood procedure. By estimating these recombination fractions separately for each kind of cross (e.g., for the backcross, using each sex as the F1 parent) and then using the larger values, we should improve our power to detect QTL and to discriminate between two QTL that are closely linked.

More work needs to be done to determine whether sex differences in recombination can be used to improve other aspects of QTL algorithms. For example it may be that sex differences in recombination will affect which method of controlling the residual genetic background (Zeng, 1994; Basten, Weir \& Zeng, 2002) works best.

Appendix

Table A1. Sex differences in recombination for diploid chiasmate species (both sexes have recombination)

\begin{tabular}{|c|c|c|c|c|c|c|c|c|}
\hline \multirow[t]{2}{*}{ Taxon } & \multirow{2}{*}{$\begin{array}{l}\text { Sexual } \\
\text { system }\end{array}$} & \multirow[t]{2}{*}{$n$} & \multicolumn{2}{|l|}{ Xta } & \multirow{2}{*}{$\begin{array}{l}\text { Map } \\
\text { ratio }\end{array}$} & \multirow[t]{2}{*}{ Diff. } & \multirow[t]{2}{*}{ Comments } & \multirow[t]{2}{*}{ Reference } \\
\hline & & & Male & Female & & & & \\
\hline \multicolumn{9}{|l|}{$\begin{array}{l}\text { Insecta: Orthoptera: Acrididae } \\
\text { (Gomphocerinae) }\end{array}$} \\
\hline Euchorthippus chopardi & $\mathrm{d}-\mathrm{XO} / \mathrm{XX}$ & 8 & 11.62 & 10.48 & - & $\mathrm{m}$ & 1 & (Cano \& Santos, 1990) \\
\hline Euchorthippus pulvinatus & $\mathrm{d}-\mathrm{XO} / \mathrm{XX}$ & 8 & 11.81 & 11.06 & - & $\mathrm{m}$ & 1 & (Cano \& Santos, 1990) \\
\hline Chorthippus vagans & $\mathrm{d}-\mathrm{XO} / \mathrm{XX}$ & 8 & 11.25 & 10.56 & - & $\mathrm{m}$ & 1 & (Cano \& Santos, 1990) \\
\hline Chorthippus parallelus & $\mathrm{d}-\mathrm{XO} / \mathrm{XX}$ & 8 & 13.38 & 11.81 & - & $\mathrm{m}$ & 1 & (Cano \& Santos, 1990) \\
\hline Chorthippus jucundus & $\mathrm{d}-\mathrm{XO} / \mathrm{XX}$ & 8 & 12.26 & 12.65 & - & $\mathrm{N}$ & 1 & (Cano \& Santos, 1990) \\
\hline Omocestus panteli & $\mathrm{d}-\mathrm{XO} / \mathrm{XX}$ & 8 & 11.8 & 11.26 & - & $\mathrm{m}$ & 1 & (Cano \& Santos, 1990) \\
\hline \multicolumn{9}{|l|}{ Chordata: Mammalia } \\
\hline Homo sapiens (Primates) & $\mathrm{d}-\mathrm{XY} / \mathrm{XX}$ & 22 & - & - & $1: 1.5$ & $\mathrm{f}$ & & (Dib et al., 1996) \\
\hline Mus musculus (Rodentia) & $\mathrm{d}-\mathrm{XY} / \mathrm{XX}$ & 19 & - & - & $1: 1.4$ & $\mathrm{f}$ & & (Dietrich et al., 1996) \\
\hline Canis familiaris (Carnivora) & $\mathrm{d}-\mathrm{XY} / \mathrm{XX}$ & 36 & - & - & $1: 1.4$ & $\mathrm{f}$ & & (Neff et al., 1990) \\
\hline $\begin{array}{l}\text { Sus domesticus } \\
\text { (Artiodactyla) }\end{array}$ & $\mathrm{d}-\mathrm{XY} / \mathrm{XX}$ & $?$ & - & - & $1: 1.4$ & $\mathrm{f}$ & & (Marklund et al., 1996) \\
\hline Ovis aries (Artiodactyla) & $\mathrm{d}-\mathrm{XY} / \mathrm{XX}$ & 26 & - & - & $1.26: 1$ & $\mathrm{~m}$ & 2 & (Crawford et al., 1995) \\
\hline Bos Taurus (Artiodactyla) & $\mathrm{d}-\mathrm{XY} / \mathrm{XX}$ & 29 & - & - & - & $\mathrm{N}$ & & (Kappes et al., 1997) \\
\hline $\begin{array}{l}\text { Monodelphis domestica } \\
\text { (Marsupialia) }\end{array}$ & $\mathrm{d}-\mathrm{XY} / \mathrm{XX}$ & 7 & - & - & $1.6: 1$ & $\mathrm{~m}$ & 1 & $\begin{array}{l}\text { (Hayman, Moore } \\
\text { \& Evans, 1988) }\end{array}$ \\
\hline $\begin{array}{l}\text { Trichosurus vulpecula } \\
\text { (Marsupialia) }\end{array}$ & $\mathrm{d}-\mathrm{XY} / \mathrm{XX}$ & 9 & 18.14 & 12.16 & $1.44: 1$ & $\mathrm{~m}$ & & $\begin{array}{l}\text { (Hayman \& Rodger, } \\
\text { 1990) }\end{array}$ \\
\hline
\end{tabular}


Table A1. (Continued.)

\begin{tabular}{|c|c|c|c|c|c|c|c|c|}
\hline \multirow[t]{2}{*}{ Taxon } & \multirow{2}{*}{$\begin{array}{l}\text { Sexual } \\
\text { system }\end{array}$} & \multirow[t]{2}{*}{$n$} & \multicolumn{2}{|l|}{ Xta } & \multirow{2}{*}{$\begin{array}{l}\text { Map } \\
\text { ratio }\end{array}$} & \multirow[t]{2}{*}{ Diff. } & \multirow[t]{2}{*}{ Comments } & \multirow[t]{2}{*}{ Reference } \\
\hline & & & Male & Female & & & & \\
\hline \multicolumn{9}{|l|}{ Chordata: Pisces } \\
\hline $\begin{array}{l}\text { Oncorhynchus mykiss } \\
\text { (Salmoniformes) }\end{array}$ & $\mathrm{d}-\mathrm{XY} / \mathrm{XX}$ & 29 & - & - & $3.25: 1$ & $\mathrm{f}$ & 2 & (Sakamoto et al., 2000) \\
\hline $\begin{array}{l}\text { Oryzias latipes } \\
\text { (Cypriniformes) }\end{array}$ & $\mathrm{d}-\mathrm{XY} / \mathrm{XX}$ & - & - & - & - & $\mathrm{f}$ & 3 & (Matsuda et al., 1999) \\
\hline \multicolumn{9}{|l|}{ Chordata: Aves } \\
\hline $\begin{array}{l}\text { Gallus domesticus } \\
\text { (Galliformes) }\end{array}$ & $\mathrm{d}-\mathrm{ZW} / \mathrm{ZZ}$ & 38 & - & - & - & $\mathrm{N}$ & 4 & (Groenen et al., 2000) \\
\hline $\begin{array}{l}\text { Columba livia } \\
\text { (Columbiformes) }\end{array}$ & $\mathrm{d}-\mathrm{ZW} / \mathrm{ZZ}$ & 38 & - & - & - & $\mathrm{N}$ & 4,5 & (Pigozzi Solari, 1999) \\
\hline \multicolumn{9}{|l|}{ Angiospermae: } \\
\hline \multicolumn{9}{|l|}{ Monocotyledonae } \\
\hline \multicolumn{9}{|l|}{ Angiospermae: } \\
\hline $\begin{array}{l}\text { Lycopersicon esculentum/ } \\
\text { pennellii (Solanaceae) }\end{array}$ & $\mathrm{h}$ & 12 & - & - & $1.19: 1$ & $\mathrm{f}$ & & $\begin{array}{l}\text { (de Vicente \& Tanks- } \\
\text { ley, 1991) }\end{array}$ \\
\hline $\begin{array}{l}\text { Brassica nigra } \\
\text { (Brassicaceae) }\end{array}$ & $\mathrm{h}$ & 8 & - & - & - & $\mathrm{N}$ & & $\begin{array}{l}\text { (Lagercrantz \& Lydi- } \\
\text { ate, 1995) }\end{array}$ \\
\hline $\begin{array}{l}\text { Brassica oleracea } \\
\text { (Brassicaceae) }\end{array}$ & $\mathrm{h}$ & 9 & - & - & $1.66: 1$ & $\mathrm{f}$ & & (Kearsey et al., 1996) \\
\hline
\end{tabular}

Sexual system $(\mathrm{h}=$ hermaphrodite; $\mathrm{d}=$ dioecious showing sex chromosome system); $n$ is the haploid number of autosomes; Xta frequency is the total number of chiasmata formed; Map ratio indicates ratio of total male to female map distance; Diff. indicates authors claim of sex difference $(\mathrm{m}=$ males greater than females; $\mathrm{f}=$ females greater; $\mathrm{N}=$ not different; parentheses indicate no statistical test).

$1=$ Sex chromosome in females cannot be distinguished from autosomes so the former are assumed to have the mean chiasma frequency.

2 = Map ratio may include sex chromosomes.

$3=$ Based on one chromosome and/or a small number of markers only.

$4=$ Actual map ratio not reported.

5 = Synaptonemal complexes and recombination nodule number used rather than chiasma frequency.

\section{References}

Barton, N.H., 1995. A general model for the evolution of recombination. Genet. Res., 65: 123-144.

Basten, C.J., B.S. Weir \& Z.-B. Zeng, 2002. QTL Cartographer. Version 1.16 edition.

Bernstein, H., F. Hopf \& R.E. Michod, 1988. Is meiotic recombination an adaptation for repairing DNA, producing genetic variation, or both?, Chapt. 9, pp. 139-160, In: The Evolution of Sex, edited by R.E. Michod \& B.R. Levin Sinauer Associates Inc., Sunderland, MA.

Borgia, G., 1979. Sexual selection and the evolution of mating systems, pp. 19-80. In: Sexual Selection and Reproductive Competition in Insects edited by M. Blum \& A. Blum. Academic Press, Inc., New York.
Bull, J.J., 1983. Evolution of Sex Determining Mechanisms. Menlo Park, Benjamin/Cummings California

Burt, A., G. Bell, \& P.H. Harvey, 1991. Sex differences in recombination. J. Evol. Biol. 4: 259-277.

Callan, H.G. \& P.E. Perry, 1977. Recombination in male and female meiocytes contrasted. Philos. T. Roy. Soc. Lond., B 277: $387-411$

Cano, M.I. \& J.L. Santos, 1990. Chiasma frequencies and distributions in gomphocerine grasshoppers: a comparative study between sexes. Heredity 64: 17-23.

Chippendale, A.K., J.R. Gibson, \& W. Rice, 2001. Negative genetic correlation for adult fitness between sexes reveals ontogenetic conflict in Drosophila. Proc. Natl. Acad. Sci., USA 98: 1671-1675. 
Coddington, J.A., 1992. Avoiding phylogenetic bias. Trends Ecol. Evol. 7: 68-69. (review of Harvey and Pagel 1991 the comparative method in evolutionary biology.)

Crawford, A.M., K.G. Dodds, A.J. Ede, C.A. Pierson, G.W. Montgomery, H.G. Garmomway, A.E. Beattie, K. Davies, J.F. Maddox, S.W. Kappes, R.T. Stone, T.C. Nguyen, J.M. Penty, E.A. Lord, J.E. Broom, J. Buitkamp, W. Schwaiger, J.T. Epplen, M.E. Matthew, P. \& Matthews, D.J. Hulme, K.J. Beh, R.A. McGraw \& C.W. Beattie, 1995. An autosomal genetic linkage map of the sheep genome. Genetics 140: 703-724.

de Vicente, M.C. \& S.D. Tanksley, 1991. Genome-wide reduction in recombination of backcross progeny derived from male versus female gametes in an interspecific cross of tomato. Theor. Appl. Genet. 83: 173-178.

Dib, C., S. Faure, C. Fizames, D. Samson, N. Drouot, A. Vignal, P. Millasseau, S. Marc, J. Hazan, E. Seboun, M. Lathrop, G. Gyapay, J. Morissette \& J. Weissenbach, 1996. A comprehensive genetic map of the human genome based on 5,264 microsatellites. Nature 380(6570): 152-154.

Dietrich, W.F., J. Miller, R. Steen, M.A. Merchant, D. Damron-Boles, Z. Husain, R. Dredge, M.J. Daly, K.A. Inballs, T.J. O'Conner, C.A. Evans, M.M. DeAngelis, D.M. Levinson, L. Kruglyak, N. Goodman, N.G. Copeland, N.A. Jenkins, T.L. Hawkins, L. Stein, D.C. Page \& E.S. Lander, 1996. A comprehensive geneic map of the mouse genome. Nature 380(6570): 149-152.

Groenen, M.A., H.H. Cheng, N. Bumstead, B.F. Benkel, W.E. Briles, T. Burke, D.W. Burt, L.B. Crittenden, J. Dodgson, J. Hillel, S. Lamont, A. Ponce de Leon, M. Soller, H. Takahashi \& A. Vignal, 2000. A consensus linkage map of the chicken genome. Genome Res. 10: 137-147.

Haldane, J.B.S., 1922. Sex ratio and unisexual sterility in hybrid animals. J. Genet. 12: 101-109.

Hayman, D.L., H.D.M. Moore \& E.P. Evans, 1988. Further evidence of novel sex differences in chiasma distribution in marsupials. Heredity 61: 455-458.

Hayman, D.L. \& J.C. Rodger, 1990. Meiosis in male Trichsurus vulpecula (Marsupialia). Heredity 64: 251-254.

Jones, A.G., G. Rosenqvist, A. Berglund, S.J. Arnold \& J.C. Avise, 2000. The Bateman gradient and the cause of sexual selection in a sex-role-reversed pipefish. Proc. R. Soc. Lond. B, Biol. Sci. 267: 677-680.

Jones, A.G., D. Walker \& J.C. Avise, 2001. Genetic evidence for extreme poyandry and extraordinary sex-role reversal in a pipefish. Proc. R. Soc. Lond., B 268: 2531-2535.

Kappes, S.M., J.W. Keele, R.T. Stone, R.A. McGraw, T.S. Sonstegard, T.P.L. Smith, N.L. Lopez-Corrales \& C.W. Beattie, 1997. A second-generation linkage map of the bovine genome. Genome Res. 7: 235-249.

Kearsey, M.J., L.D. Ramsay, D.E. Jennings, D.J. Lydiate, E.J.R. Bouhuon \& D.F. Marshall, 1996. Higher recombination frequencies in females compared to male meioses in Brassica oleracea. Theor. Appl. Genet. 92: 363-367.

Korol, A.B., I.A. Preygel \& S.I. Preygel, 1994. Recombination Variability and Evolution: Algorithms of Estimation and Population-Genetic Models. Chapman and Hall, London.

Lagercrantz, U. \& D.J. Lydiate, 1995. RFLP mapping in Brassica nigra indicates differeing recombination rates in male and female meiosis. Genome 38: 255-264.
Liu, B.H., 1998. Statistical Genomics: Linkage, Mapping, and QTL Analysis. CRC Press, Boca Raton.

Marklund, L., M. Johansson Moller, B. Høyheim, W. Davies, M. Fredholm, R.K. Juneja, P. Mariani, W. Coppieters, H. Ellegren \& L. Andersson, 1996. A comprehensive linkage map of the pig based on a wild pig-Large White intercross. Anim. Genet. 27: 255-269.

Matsuda, M., S. Sotoyama, S. Hamaguchi \& M. Sakaizumi, 1999. Male-specific restriction of recombination frequency in the sex chromosomes of the medaka, Oryzias latipes. Genet. Res. 73: 225-231.

Neff, M.W., K.W. Broman, C.S. Mellersh, K. Ray, G.M. Acland, G.D. Aguirre, J.S. Ziegle, E.A. Ostrander \& J. Rine, 1990. A second-generation genetic linkage map of the domestic dog, Canis familiaris. Genetics 151: 803-820.

Nei, M., 1969. Linkage modification and sex difference in recombination. Genetics 63: 681-699.

Otto, S.P. \& Y. Michalakis, 1998. The evolution of recombination in changing environments. Trends Ecol. Evol. 13: 145-151.

Phillips, P.C., S.P. Otto \& M.C. Whitlock, 2000. Beyond the average: the evolutionary importance of gene interactions and variability of epistatic effects, Chapter 2, pp. 20-38. In: Epistasis and the Evolutionary Process, edited by J.B. Wolf, E.D. Brodie \& M.J. Wade Oxford University Press, New York, NY.

Pigozzi, M. \& A. Solari, 1999. Equal frequencies of recombination nodules in both sexes of the pigeon suggest a basic difference with eutherian mammals. Genome 42: 315-321.

Robertson, D.S., 1984. Different frequency in the recovery of crossover products from male and female gametes of plants hypoploid for B-A translocations in Maize. Genetics 107: $117-130$.

Rowe, L. \& D. Houle, 1996. The lek paradox and the capture of genetic variance by condition dependent traits. Proc. R. Soc. Lond. B, Biol. Sci. 263: 1415-1421.

Sakamoto, T., R.G. Danzmann, K. Gharbi, P. Howard, A. Ozaki, S. Kean Khoo, R.A. Woram, N. Okamoto, M.M. Ferguson, L.-E. Holm, R. Guyomard \& B. Hoyheim, 2000. A microsatellite linkage map of rainbow trout (Oncorhynchus mykiss) characterized by large sex-specific differences in recombination rates. Genetics 155: 13311345.

Singer, A., H. Perlman, Y. Yan, C. Walker, G. Corley-Smith, B. Brandhorst \& J. Postlethwait, 2002. Sex-specific recombination rates in zebrafish (Danio rerio). Genetics 160: 649-657.

Trivers, R.L., 1988. Sex differences in rates of recombination and sexual selection. pp. 270-286. in: The Evolution of Sex, edited by R.E. Michod \& B.R. Levin. Sinauer Associates Inc., Sunderlan, Massachusetts.

van Oorschot, R.A.H., P.A. Porter, C.M. Kammerer \& J.L. VandeBerg, 1992. Severely reduced recombination in females of the South American marsupial Monodelphis domestica. Cytogenet. Cell Genet. 60: 64-67.

Watson, I.D. \& H.G. Callan, 1963. The form of bivalent chromosomes in newt oocytes at first meaphase of meiosis. Q. J. Microsc. Sci. 104: 281-295.

Zeng, Z.-B., 1994. Precision mapping of quantitative trait loci. Genetics 136: 1457-1466. 